\title{
Coupling Isoelectric Focusing Gel Electrophoresis to Mass Spectrometry by Electrostatic Spray Ionization
}

\author{
Liang Qiao, ${ }^{\S \dagger}$ Elena Tobolkina, ${ }^{\S, \dagger}$ Baohong Liu, ${ }^{\ddagger}$ and Hubert H. Girault*, ${ }^{\dagger}$ \\ ${ }^{\dagger}$ Laboratoire d’Electrochimie Physique et Analytique, Ecole Polytechnique Fédérale de Lausanne, Station 6, CH-1015 Lausanne, \\ Switzerland \\ ${ }^{\ddagger}$ Department of Chemistry and Institute of Biomedical Sciences, Fudan University, Shanghai, 200433, P.R. China
}

Web-Enhanced Feature S Supporting Information

ABSTRACT: Gel electrophoresis has been used for decades as a highresolution separation technique for proteins and protein isomers but has been limited in the coupling with MS because of low throughput and poor automaticity compared with LC-MS. In this work, we have developed an ambient ionization strategy, electrostatic spray ionization, for in situ ionization of proteins or peptides inside a surfactant-free polyacrylamide gel. The samples can be first separated by isoelectric focusing in a gel and then quickly in situ detected by scanning the gel with the electrostatic spray ionization mass spectrometry. With this strategy, nanograms of proteins or peptides inside a band are enough to be ionized for MS detection. This method for protein/ peptide spots visualization is sensitive, providing sample molecular weight information while avoiding spot staining and chemical extraction procedures that can introduce contaminants and sample loss. Proof-of-principle results

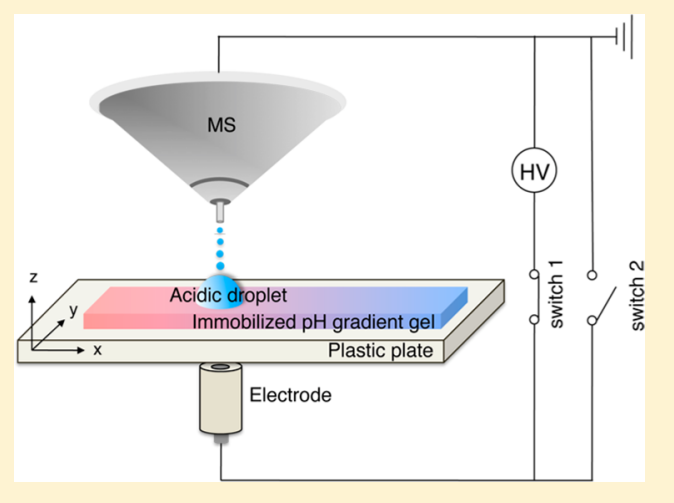
have demonstrated that the electrostatic spray ionization can produce sample ions from a complex background, and with a spatial resolution matching the isoelectric focusing, it is therefore a good choice to couple directly isoelectric focusing gel electrophoresis with mass spectrometry.

S ystem biology and proteomics require advanced analytical strategies. To analyze a large set of biomolecules, various analytical methods are usually combined, including high resolution separation techniques, sensitive detection tools and high throughput data processing software. ${ }^{1}$ With the development of soft ionization strategies, such as matrix-assisted laser desorption/ionization (MALDI) ${ }^{2,3}$ and electrospray ionization (ESI), ${ }^{4,5}$ to produce intact molecular ions, mass spectrometry (MS) has been extensively used for characterizing the structure of proteins and peptides. ${ }^{1}$

Nowadays, the most widely used and developed proteomics strategy is bottom-up proteomics, where the proteins are digested into peptides followed by liquid chromatography (LC)-MS/MS detection. ${ }^{6}$ The advantages of this strategy include high throughput and good sensitivity. However, it is also largely limited by the facts that proteins are normally identified based only on the detection of several peptides and that the sequence coverage in general is quite low. This makes the complete structure characterization of proteins very difficult, especially the post-translational modifications (PTMs). ${ }^{7}$

Jungblut et al. have suggested the concept of "protein species", indicating that modifications on proteins lead to new molecules with different functions. ${ }^{7,8}$ Recently, the Consortium for Top Down Proteomics suggested the term "Proteoform" to designate all the molecular forms in which the protein product of a single gene can be found, including changes due to genetic variations, alternatively spliced RNA transcripts and posttranslational modifications. ${ }^{9}$ Protein species proteomics or Proteoform requires complete separation of proteins and structure analysis of single protein species. Therefore, topdown proteomics strategies are needed, involving techniques such as high-resolution sample separation, high-resolution MS and fragmentation of protein ions in the gas phase. ${ }^{10}$ Compared with bottom-up proteomics, top-down proteomics is limited by the current techniques in analytical chemistry, and suffers the drawbacks such as low throughput and sensitivity. Nevertheless, novel top-down proteomics strategies have already been proposed. To date, Smith and Paša-Tolić have realized the characterization of protein isoforms and modifications by combining the top-down and bottom-up strategies based on Fourier transform ion cyclotron resonance (FTICR)-MS and LC separation of proteins. ${ }^{11,12}$ Kelleher et al. have developed a strategy for mapping intact protein isomers by combining 4 separation systems of isoelectric focusing (IEF), gel-eluted liquid fraction entrapment electrophoresis (GELFrEE), nanoLC and MS. ${ }^{13}$

Even before the concept of proteomics, gel electrophoresis has been used for fractionation of complex cellular extract into protein spots visualized by staining. ${ }^{10}$ High-resolution two-

Received: February 12, 2013

Accepted: March 19, 2013

Published: March 19, 2013 
dimensional gel electrophoresis (2-D gel) combines isoelectric focusing (IEF) and SDS polyacrylamide gel electrophoresis. ${ }^{14,15}$ IEF is a technique developed through the 20th century by the efforts of many scientists, such as Vesterberg ${ }^{16}$ Fawcett $^{17}$ and many others. Up to now, IEF electrophoresis has been the high-resolution technique of choice for separating amphoteric species according to their isoelectric points ( $\mathrm{pI}$ ) under the application of an electric field. ${ }^{18}$ IEF electrophoresis can be realized with various platforms, including capillary electrophoresis (CE), ${ }^{19}$ OFFGEL electrophoresis ${ }^{20}$ developed in our laboratory or simply gel electrophoresis using either a $\mathrm{pH}$ gradient gel or mobile ampholytes in a polyacrylamide gel. ${ }^{21}$ After gel IEF, the biomolecules are either stained, for example, by Coomassie Brilliant Blue or silver and then extracted in a buffer for subsequent MS identification or LC-MS analysis, or are denatured for SDS electrophoresis. ${ }^{22}$ In these protocols, procedures for in-gel digestion, chemical extraction and desalting are required, which are normally time-consuming and incomplete leading to sample loss, making the coupling of gel electrophoresis with MS a low throughput process difficult to automate. As a result, the 2D-gel-MS is less used than LCMS in proteomics although $2 \mathrm{D}$-gel is the high-resolution technique of choice for protein separation. It is very important to develop new ionization techniques for directly coupling IEFgel electrophoresis to MS in a highly automatic manner without the time-consuming steps of sample spot staining and chemical extraction of samples from the gel.

Ionization is a key step in mass spectrometry to transform sample species into gas phase ions. This important step can be performed under vacuum or at atmospheric pressure. Most MALDI techniques are realized under vacuum. Recently, vacuum ionization techniques have been developed by Trimpin et al., where the ionization is mainly induced by the reduced pressure but not the high voltages nor a laser beam. ${ }^{23,24}$ The development of ambient ionization is useful for fast analysis of untreated samples. Classical ESI is the most widely used ambient ionization technique; while other techniques such as desorption electrospray ionization (DESI) developed by Cooks et al. $^{25}$ are extending the analytical applications. Recently, we have developed an electrostatic spray ionization (ESTASI) method, which is also an ambient ionization strategy, to in situ generate molecular ions from untreated samples on an insulating surface. ${ }^{26}$

In the present work, ESTASI is adapted to IEF gel electrophoresis, where charged samples in a gel were directly extracted by an electric field and then electro-sprayed for MS detection. According to our knowledge, it is the first attempt to in situ ionize samples inside an IEF gel. As a result of the ionization principle being similar to ESI, the limited tolerance to salts and SDS is still a challenge for extending the present ESTASI approach to other gel separation methods. Nevertheless, proof-of-concept results were obtained for ESTASI-MS analysis of proteins and peptides separated by IEF in immobilized $\mathrm{pH}$ gradient (IPG) gel with limits of detection (LOD) in the range of low nanograms, indicating a strategy for sample spots visualization that is sensitive, avoids chemical extraction procedures and provides molecular weight information at the same time. Since IEF gel electrophoresis is a highresolution separation technique for proteins and especially protein isomers, ${ }^{27}$ the gel ESTASI-MS has potential application in top-down proteomics with the development of other techniques, such as gas phase fragmentation of large proteins, ultrahigh resolution mass spectrometers and dedicated data processing software. Furthermore, since the ionization was realized within an untreated gel after IEF, such strategy can be performed in a high throughput manner with the help of automatic positioning system.

\section{EXPERIMENTAL SECTION}

Materials. Immobilized $\mathrm{pH}$ gradient gels (Immobiline Dryplate $\mathrm{pH} 4$ to 7) were purchased from Amersham Biosiences (Uppsala, Sweden). Cytochrome c from horse heart $(12.3 \mathrm{kDa})$, myoglobin from horse skeletal muscle (17 $\mathrm{kDa}$ ), bovine serum albumin (BSA, 66.4 kDa) and iodoacetamide (crystalline) were obtained from Sigma-Aldrich (Schnelldorf, Switzerland) as well as methanol and acetic acid of the purest grade (>99.9\%). Trypsin (bovine pancreas, 23.8 $\mathrm{kDa}$ ) was from AppliChem $\mathrm{GmbH}$ (Darmstadt, Germany). Angiotensin I ( $\left.\mathrm{NH}_{2}-\mathrm{DRVYIHPFHL}-\mathrm{COOH}, 98 \%\right)$ was obtained from Bachem (Switzerland). 1,4-Dithiothreitol $(\geq 99 \%)$ was purchased from Fluka. Deionized water was purified by an alpha QMillipore system (Zug, Switzerland) and used in all aqueous solutions.

BSA Digestion. Forty microliters of $100 \mathrm{mM}$ ammonium bicarbonate $\left(\mathrm{NH}_{4} \mathrm{HCO}_{3}\right)$ was added to $100 \mu \mathrm{L}$ of bovine serum albumin solution $(87 \mu \mathrm{M})$. Afterward, $5 \mu \mathrm{L}$ of $200 \mathrm{mM}$ 1,4-dithiothreitol (DTT) was added and the mixture was incubated at $95{ }^{\circ} \mathrm{C}$ for $5 \mathrm{~min}$. Ten microliters of $200 \mathrm{mM}$ iodoacetamide (IAA) was tacked and the solution was incubated for $20 \mathrm{~min}$ at room temperature in dark. Finally, trypsin was added with a final ratio of $1: 30$ (w/w, trypsin:protein), incubated at $37{ }^{\circ} \mathrm{C}$ for $20 \mathrm{~h}$. The tryptic digests of BSA was stored under $-20{ }^{\circ} \mathrm{C}$.

Soluble Escherichia coli Protein Extract Preparation. An overnight $200 \mathrm{~mL}$ culture of Escherichia coli (E. coli, strain $\mathrm{DH} 5 \alpha$ ) was collected by $10 \mathrm{~min}$ centrifugation at $5000 \times g$ and $4{ }^{\circ} \mathrm{C}$. The cell pellet $(0.6 \mathrm{~g}$ wet weight $)$ was resuspended in 3 $\mathrm{mL}$ of lysis buffer (50 mM Tris-HCl, $\mathrm{pH} 7.5,5 \mathrm{mM}$ EDTA) and cells were disrupted by sonication $(10 \times 10$ pulses of $1 \mathrm{~s}$ at $30 \mathrm{~W})$. Cell debris were removed by $10 \mathrm{~min}$ centrifugation at $2000 \times g$. Ultracentrifugation $\left(1 \mathrm{~h}\right.$ at $100000 \times g$ at $\left.4{ }^{\circ} \mathrm{C}\right)$ was applied to the total cell extract to remove membranes and membrane-bound proteins. The supernatant was collected and was considered as the soluble fraction of E. coli proteins.

Gel Electrophoresis. The gel strips were cut from the Immobiline Dryplate $\mathrm{pH} 4$ to 7 and then reswelled in water for one hour before use. Depending on the application, gel strips with constant $\mathrm{pH}$ or $\mathrm{pH}$ gradient were prepared. After loading samples on the gel strips, electrophoresis was performed under different conditions according to the application. After electrophoresis, the gels were washed with water in order to remove any proteins staying on the surface of the gel before ESTASI-MS analysis.

For analyzing cytochrome c, the electrophoresis was performed on a constant $\mathrm{pH} 4$ gel strip under $300 \mathrm{~V}$ and 1 $\mathrm{mA}$ for 10 min with an EPS 3501 XL power supply (Amersham Pharmacia Biotech, Sweden). For analyzing angiotensin I, the electrophoresis was performed on a gel strip with $\mathrm{pH}$ gradient 4 to 5.2 under the conditions of voltage applied $=500 \mathrm{~V}$ and limiting current $=100 \mu \mathrm{A}$ for $30 \mathrm{~min}$ with the Agilent Fractionator 3100. For analyzing BSA digests, IEF was performed by Agilent Fractionator 3100 on gel strips with $\mathrm{pH}$ gradient 4 to 7 under the condition of maximum current $=$ $150 \mu \mathrm{A}$ and voltage applied up to $4000 \mathrm{~V}$ until $10 \mathrm{kVh}$ reached in $4 \mathrm{~h}$. For analyzing E. coli protein extract spiked with myoglobin and cytochrome c, IEF was performed with the 
Scheme 1. Schematic Representation of the Electrostatic Spray Ionization from a Polyacrylamide Gel ${ }^{a}$

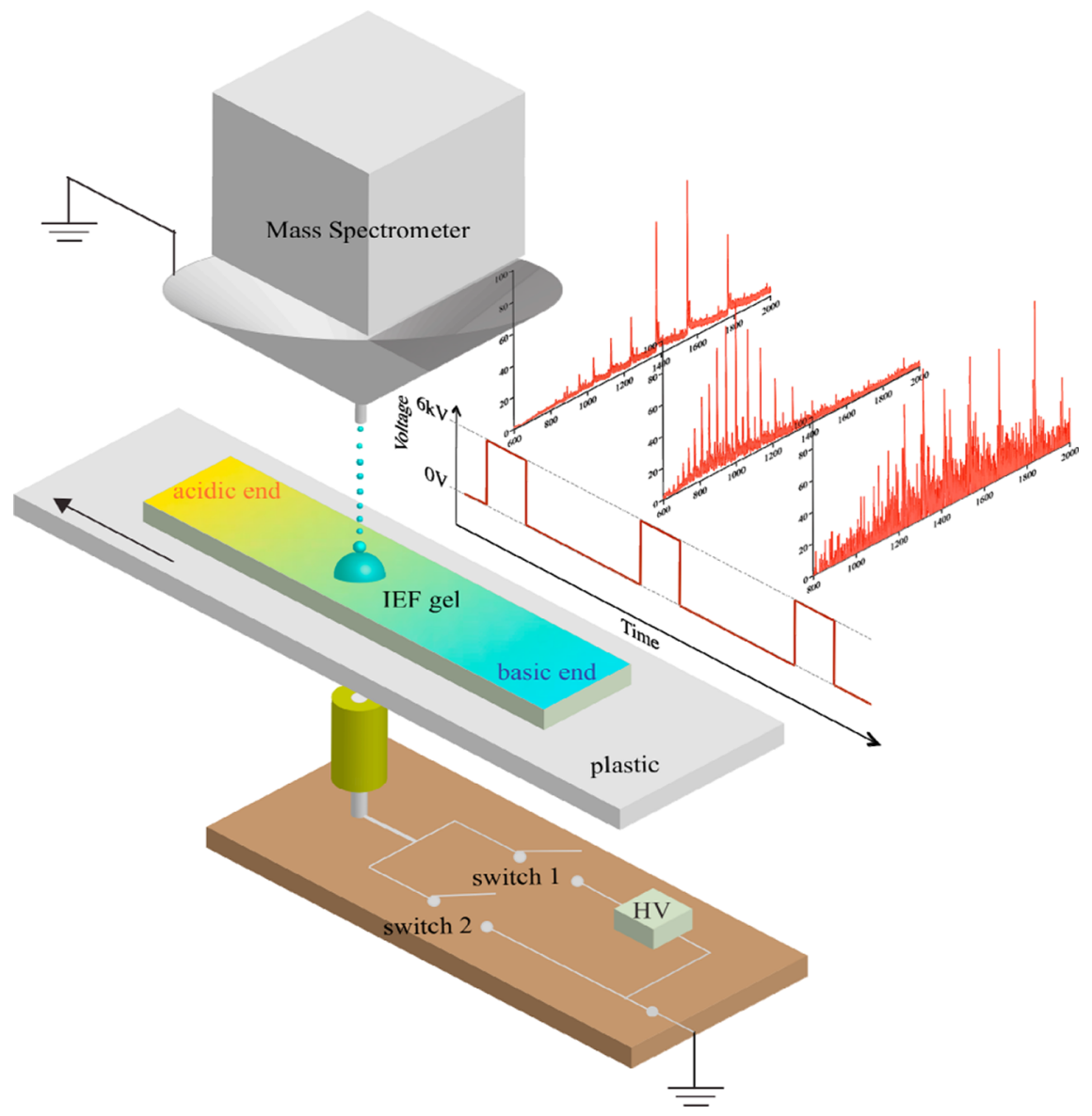

${ }^{a} \mathrm{HV}$, high voltage.

following voltage program: $1 \mathrm{~h}$ at $500 \mathrm{~V}$, then $1 \mathrm{~h}$ at $1000 \mathrm{~V}$, and finally $5 \mathrm{~h}$ at $5000 \mathrm{~V}$. The current limit was set at $150 \mu \mathrm{A}$. $400 \mu \mathrm{g}$ of E. coli protein extract, $4 \mu \mathrm{g}$ of myoglobin and $4 \mu \mathrm{g}$ of cytochrome $c$ were loaded on the gel.

Gel on a Plastic Support Drilled with Holes. The Immobiline Dryplate gel is commercially fixed on a $0.2 \mathrm{~mm}$ GelBond PAG film. Arrays of holes (1 $\mathrm{mm}$ in diameter) were drilled on the film by laser ablation through a metallic mask by a 193 nm ArF excimer laser beam (Lambda Physik, Göttingen, Germany, fluence $=0.2 \mathrm{~J}$, frequency $=50 \mathrm{~Hz}$ ). In total, 2 lines of 10 holes were drilled on the film with the distance of $2 \mathrm{~mm}$ between each other. It is important to control the laser to just penetrate the plastic film while not burning the gel.

Gel-ESTASI-MS. Two strategies were used for IEF gelESTASI-MS. In the first strategy, droplets of an acidic buffer (50\% methanol, $49 \%$ water and $1 \%$ acetic acid) were deposited manually on top of the gel that was fixed on a $0.2 \mathrm{~mm}$ GelBond PAG film. The ESTASI was performed as illustrated in Scheme 1. In the second strategy, ESTASI was performed with the help of a plastic support drilled with holes. The gel was placed between two pieces of $0.2 \mathrm{~mm}$ GelBond PAG film, where one was drilled with holes by laser ablation. The holes were filled with the acidic buffer, and the ESTASI was performed as illustrated in Scheme 3.

In both cases, an electrode was placed behind the bottom plastic layer and the gel or part of the gel was placed close to the MS inlet to induce the electrostatic spray ionization (Schemes 1 and 3). The electrode was connected with a DC high voltage $(6.5 \mathrm{kV})$ source via switch 1 or grounded via switch 2. A special LabView program was written to control the switches in order to synchronize their work. Warning: Cables with ferrite bead should be used to avoid high frequency noise of $H V$.

A linear ion trap mass spectrometer of Thermo LTQ Velos was used to detect the ions produced by ESTASI, where the MS inlet was always grounded. The spray voltage of the internal power source of the MS was set as 0 . An enhanced ion trap scanning rate $(10000 \mathrm{amu} / \mathrm{s})$ was used. For the analysis of BSA digest, the mass-to-charge ratios of peaks were read out to compare with the molecular weights of all the possible peptides generated from BSA by trypsin digestion. Online tools of FindPept and FindMod from ExPASy (www.expasy.org) were used to help the comparison.

Gel-based IEF-MALDI-MS. The IEF of BSA digest was performed using an IPG strip with same protocol described in Gel electrophoresis. After the IEF, the peptides were eluted from the IPG strip, using a Nanosep centrifugal device (Pall Life Sciences, Ann Arbor, MI) following the protocol provided by the company (http://www.pall.com/main/Laboratory/ Literature-Library-Details.page?id=2273). Each extracted fraction was first completely lyophilized and then dissolved in 30 $\mu \mathrm{L}$ of water. Two $\mu \mathrm{L}$ solution from each fraction was deposited on a MALDI plate and dried under ambient conditions. Afterward, $1 \mu \mathrm{L}$ matrix solution $(10 \mathrm{mg} / \mathrm{mL} 2,5$-dihydroxybenzoic acid in 50\% methanol, $49 \%$ water and $1 \%$ acetic acid) was deposited on the sample and also dried under ambient 
conditions. The MALDI-MS analysis was performed on a Bruker MicroFlex LRF under reflectron positive ionization mode.

OFFGEL IEF-ESI-MS. The Agilent Fractionator 3100 was used for OFFGEL separation of peptides. A 18-cm-long IPG gel strip with a liner $\mathrm{pH}$ gradient ranging from 4 to 7 was rehydrated in water for $1 \mathrm{~h}$. Fifty microliters of BSA digest (56 $\mu \mathrm{M}$ ) was diluted with water to a final volume of $2.7 \mathrm{~mL}$, and $150 \mu \mathrm{L}$ of sample was loaded into each well (18 wells in total). The sample was then focused using the potential program with a maximum current of $50 \mu \mathrm{A}$, voltages ranging up to $8000 \mathrm{~V}$ until $64 \mathrm{kVh}$ reached after $24 \mathrm{~h}$. The recovered fractions (140 $\mu \mathrm{L}$ each) from each of the 18 wells were first lyophilized and then dissolved in $40 \mu \mathrm{L}$ acidic buffer (50\% methanol, $49 \%$ water and $1 \%$ acetic acid), respectively, for ESI-MS (Thermo LTQ velos) analysis. The standard commercial ESI source was used to produce ions from the solutions under infusion mode with a high voltage of $3.7 \mathrm{kV}$ and a sample flow rate of $3 \mu \mathrm{L} /$ min.

Numerical Simulation. Numerical simulation was performed using finite element package COMSOL Multiphysics (version 3.5a) installed on a Mac Pro with four $2.66 \mathrm{GHz}$ central processing units and $9.8 \mathrm{~GB}$ of RAM operating under Linux Ubuntu 8.04 platform. Electric field distribution in the polyacrylamide gel was simulated in a two-dimensional axis symmetry computational domain utilizing Laplace equation. For the finite element simulation the relative permittivity values for air, water, and insulating plastic plate were taken from the Handbook of Chemistry and Physics (http://www. hbcpnetbase.com/). Other parameters used in the simulations were from the experiments, such as diameter of the hole drilled in the plastic cover $(1 \mathrm{~mm})$, the electrode diameter $(2 \mathrm{~mm})$, the insulating plate thickness (top and bottom, $0.2 \mathrm{~mm}$ ), and the gel thickness $(0.5 \mathrm{~mm})$.

\section{RESULTS AND DISCUSSION}

Electrostatic Spray Ionization of Peptide or Protein from Polyacrylamide Gel. The ESTASI-MS detection of samples inside polyacrylamide gel is schematically represented in Scheme 1. An immobilized $\mathrm{pH}$ gradient (IPG) strip containing fractions of proteins or peptides and supported on a thin piece of insulating polymer layer is placed in front of the MS inlet. An electrode is placed behind the plastic substrate and connected intermittently either to a direct current (DC) high voltage source or to ground using a pair of synchronized switches. A droplet of acidic buffer (49\% water, 50\% methanol and $1 \%$ acetic acid) is deposited on the gel between the electrode and the MS inlet. Upon application of a high voltage pulse, the droplet becomes polarized and as soon as the charge is large enough at the apex of the droplet for the electrostatic pressure to be larger than the Laplace pressure, a spray pulse of charged microdroplets occurrs. When grounding the electrode again, a pulse spray of counter charges takes place to reestablish the electroneutrality of the droplet. For a positive high voltage, the cycle includes therefore first spray of cations and then of anions. By repeating this cycle at a given frequency, a series of pulsed sprays are realized. This method is simple and can be used to analyze the separated sample components directly from a polyacrylamide gel without the need of extra processing steps. Details of the electronic circuit and the Labview program used to synchronize the two switches are given in Supporting Information SI-1. A video of the droplet undergoing ESTASI is also shown as Movie 1.
To detect samples from a gel strip by ESTASI-MS, it is important to ensure that the analytes can be extracted into the droplets. In a first simple approach, acidic buffer droplets $(\mathrm{pH}=$ 2) were deposited by hand on an IPG strip with $\mathrm{pH}$ from 4 to 7. Because of the strong acidity of the droplets, peptides or proteins under the droplets became positively charged. When the positive high voltage was applied, these positively charged species were extracted into the droplets by the electric field as shown in Scheme 2. To guarantee an efficient extraction,

Scheme 2. Schematic Representation of Protein or Peptide Extraction from the Polyacrylamide Gel by Applying High Voltage $^{a}$

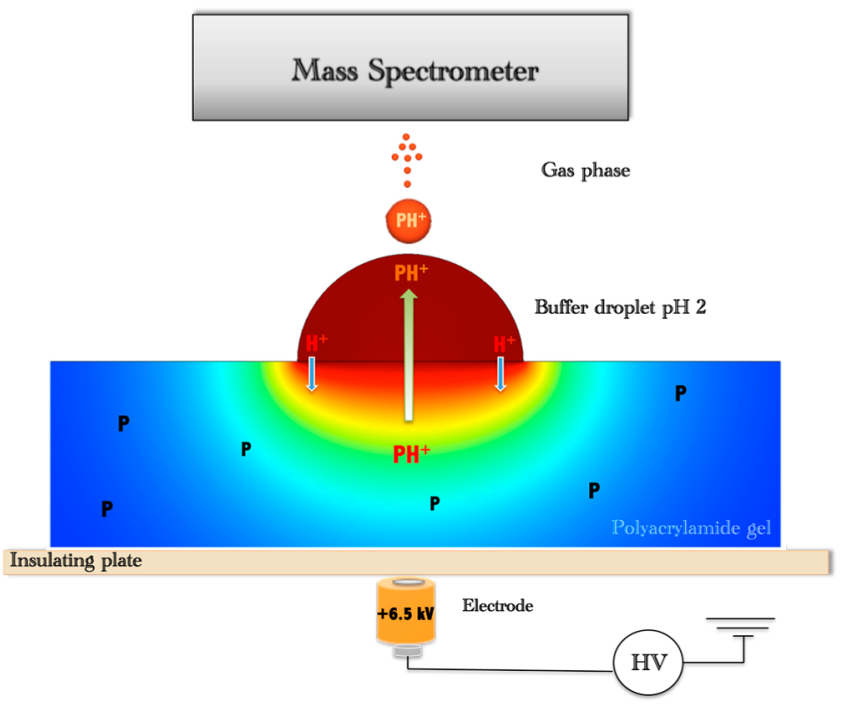

${ }^{a} \mathrm{P}$, protein or peptide; $\mathrm{PH}^{+}$, protonated protein or peptide. The color gradient shows the diffusion of proton in a polyacrylamide gel obtained by finite element simulation with COSMOL Multiphysics.

different time sequences were tested to optimize the extractionionization process. It was found that a long extraction time was preferable for acquiring good mass spectra and the optimized time sequence was set: $t 1=t 4=3 \mathrm{~s}, t 2=9 \mathrm{~s}$ and $t 3=6 \mathrm{~s}(t 1 \ldots t 4$ are defined in Supporting Information Scheme SI-1.2).

With this simple approach based on the deposition of acidic droplets on top of the gel, the detection of cytochrome $\mathrm{c}$ in a gel strip using a linear ion trap mass spectrometer (Thermo LTQ Velos) was realized. Droplets ( $1 \mu \mathrm{L}$ each) of cytochrome c solution with different concentrations $(0.2 \mathrm{mg} / \mathrm{mL}$ and 0.02 $\mathrm{mg} / \mathrm{mL}$ ) were loaded on a constant $\mathrm{pH} 4$ gel strip. An electrophoresis was performed for $10 \mathrm{~min}(300 \mathrm{~V}, 1 \mathrm{~mA})$ with an EPS $3501 \mathrm{XL}$ power supply (Amersham Pharmacia Biotech, Sweden) to migrate the sample and ensure that the sample has well penetrated within the gel. Afterward, the gel was washed briefly with water in order to remove any proteins present on the surface of the gel. Since cytochrome $c$ is colored, the protein band could be observed when the concentration was high $(0.2 \mathrm{mg} / \mathrm{mL})$, making the ESTASI-MS detection easy. When the concentration was lower, the gel was scanned by the ESTASI-MS to locate the protein band.

Figure la shows one of the mass spectra of cytochrome c generated by ESTASI-MS, where the amount of protein in the band was at most $200 \mathrm{ng}(16.3 \mathrm{pmol})$. Indeed, several pulses of ESTASI could happen when one droplet $(1 \mu \mathrm{L})$ of the acidic buffer was deposited on the gel, resulting in several effective 
(a)

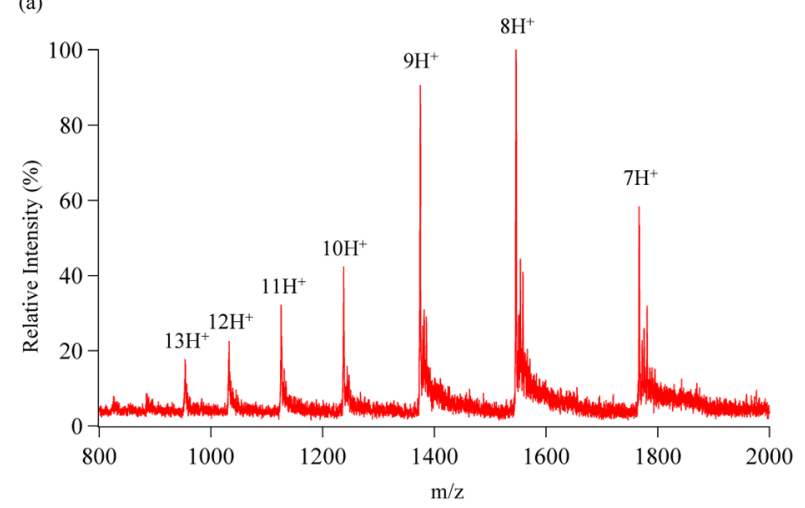

(b)

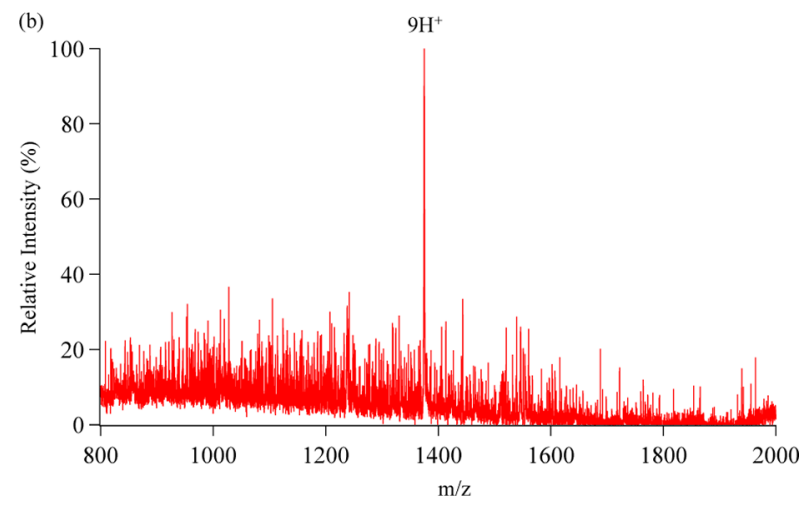

Figure 1. Mass spectra of cytochrome c with the amount of (a) $200 \mathrm{ng}$ and (b) $20 \mathrm{ng}$ in a polyacrylamide gel. The ions were generated by ESTASI when a pulsed positive high potential $(6.5 \mathrm{kV})$ was applied to the electrode and when $1 \mu \mathrm{L}$ of the acidic buffer was deposited on the gel.

mass spectra obtained by the MS. The pulsed spray nature of ESTASI is beneficial to limit sample consumption.

When the amount of proteins in a band was too low, the concentration of proteins extracted into the droplet would also be too low to be detected by MS. With the current setup and a linear ion trap mass spectrometer (Thermo LTQ Velos), the limit of detection (LOD) of cytochrome $\mathrm{c}$ in a band was found to be $20 \mathrm{ng}(1.63 \mathrm{pmol})$, shown as Figure $1 \mathrm{~b}$. In practice, a higher sample amount is preferred since the observation of only one charge state is usually not sufficient for protein detection. There is a gap between the LOD of MS, which is normally in the low fmol range, and the in-gel ESTASI-MS strategy, which is in the low pmol range. However, the current gel profiling method is as good as or better than the classic Coomassie Brilliant Blue staining that normally needs 50-100 ng of protein in a band. With the direct ionization of samples from gel by ESTASI, a maximum usage of the samples is guaranteed, and thereby further improvement of LOD and sensitivity can be expected by optimizing the gel preparation and the ionization device.

Angiotensin I peptide ( $\mathrm{NH}_{2}$-DRVYIHPFHL-COOH) was selected as a model sample to evaluate the ESTASI-MS detection of peptides in gel. One microliter of $20 \mu \mathrm{M}$ angiotensin I solution was loaded on top of a gel strip with a $\mathrm{pH}$ range from 4 to 5.2. Gel electrophoresis was performed with the Agilent Fractionator 3100. Considering the isoeletric point ( $\mathrm{pI}$ ) of angiotensin I of 6.9, the peptide should migrate till the cathode after applying the voltage. Shown as Figure 2, the peptides were easily detected by ESTASI-MS after the electrophoresis by scanning the gel near the cathode area,
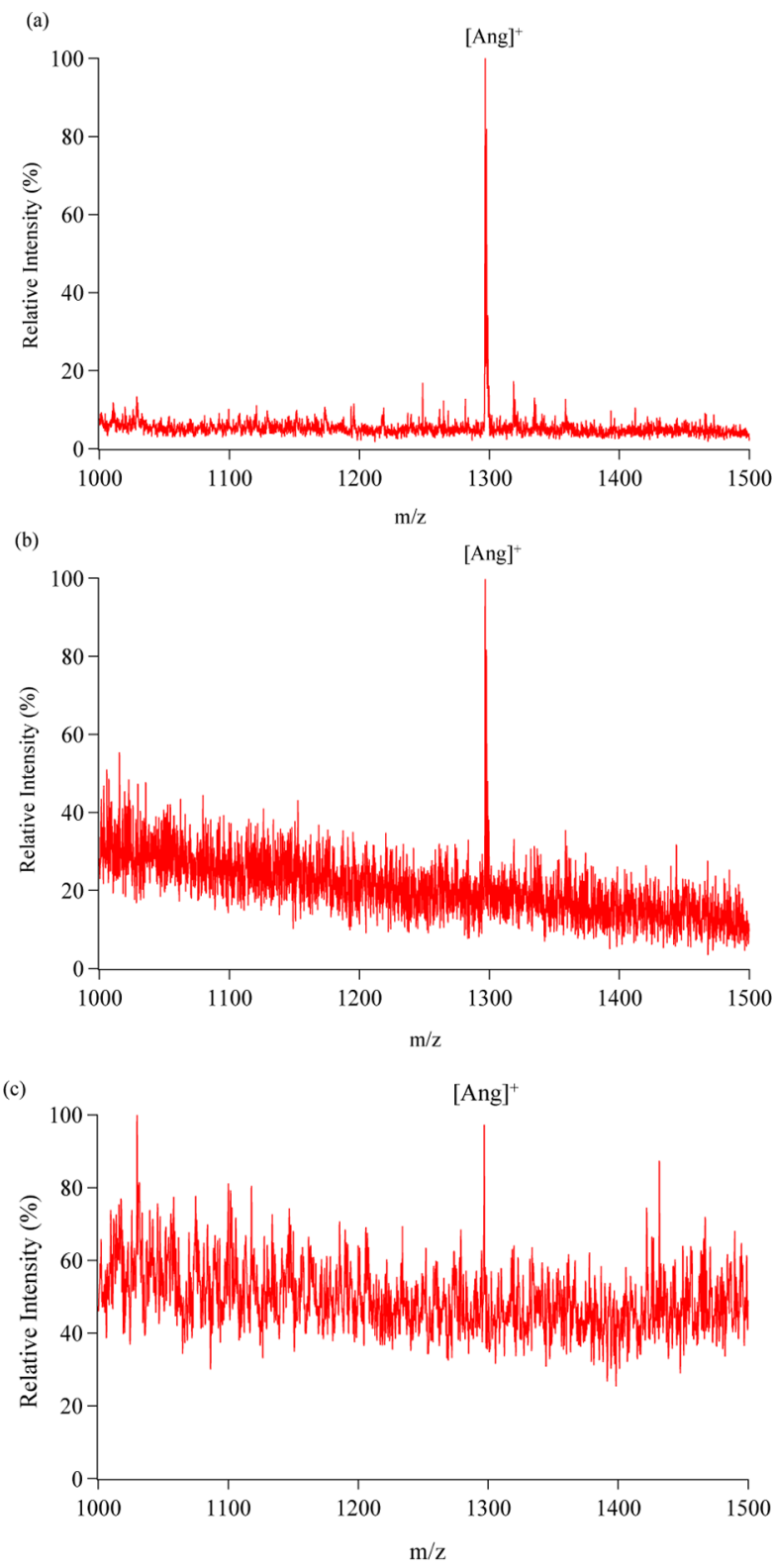

Figure 2. Mass spectra of angiotensin I with the amount of (a) 20 pmol, (b) 5 pmol and (c) 1 pmol in the gel with a $\mathrm{pH}$ range from 4 to 5.2 under positive MS mode. The ions were generated by ESTASI when a pulsed positive high potential $(6.5 \mathrm{kV})$ was applied to the electrode.

where the amount of peptide in the band was $26 \mathrm{ng}(20 \mathrm{pmol})$ in maximum. When the amount of angiotensin I was decreased to $6.5 \mathrm{ng}(5 \mathrm{pmol})$, it was still easily detected by ESTASI-MS after IEF, Figure $2 b$. The LOD for ESTASI-MS in-gel detection of peptide was found to be $1.3 \mathrm{ng}(1 \mathrm{pmol})$, Figure $2 \mathrm{c}$, comparable to the LOD of protein by the in-gel ESTASI-MS.

Spatial Resolution of ESTASI and IEF. To go further toward practical applications the in-gel ESTASI was used to combine MS and IEF gel electrophoresis. It is then important for ESTASI to have a spatial resolution comparable to that of IEF. The spatial resolution of ESTASI is mainly determined by the electrode size and the droplet size. A plastic cover drilled with holes ( $1 \mathrm{~mm}$ in diameter) was placed on top of the gel as shown in Scheme 3. The drilled holes can be filled with acidic buffer to control accurately the droplet size and thereby the 
Scheme 3. Schematic Illustration of the ESTASI-MS Analysis of Proteins in Gel When a Plastic Cover Patterned with Holes Was Used

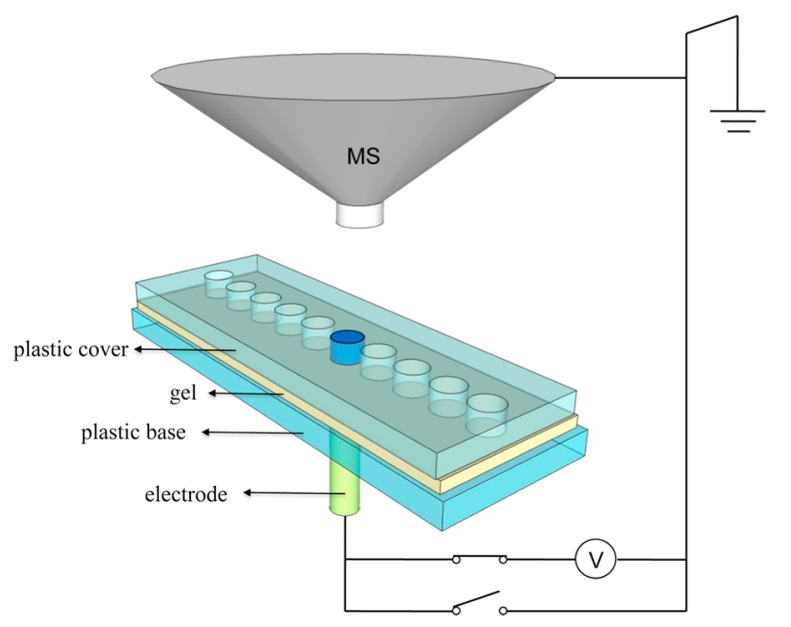

spatial resolution of ESTASI. The holes can also be used for locating the spray position. As shown in Supporting Information Figure SI-2, ESTASI-MS worked well when a plastic cover patterned with holes was fixed on a gel containing cytochrome c.

The spatial resolution of ESTASI is mainly determined by the geometry of the cover and the electrode diameter. According to Scheme 2, charged proteins/peptides can be extracted from the gel to the droplet by electric field for ESTASI-MS detection. Therefore, the electric field in the gel determines the spatial resolution of ESTASI. Figure 3 represents the strong electric field in the gel given in $\mathrm{V} / \mathrm{m}$ units. As it can be found from the calculations the spatial resolution is $\sim 3 \mathrm{~mm}$. Better resolution can be achieved by drilling smaller holes and using electrodes with smaller diameters, Supporting Information SI-3.

In IEF, the separation resolution is influenced by electric field strength, gel $\mathrm{pH}$ gradient and temperature. Normally, the buffer effect of the ampholyte molecules in gel generates a $\mathrm{pH}$ gradient with the resolution reaching $0.001 \mathrm{pH}$ units, which allows the separation of proteins with $\mathrm{p} I$ differences of $0.02 \mathrm{pH}$ units. ${ }^{28}$ IPG strip with $\mathrm{pH}$ gradient of $\sim 0.01 \mathrm{pH} / \mathrm{mm}$ was used in the current work. Therefore, the optimized spatial resolution of IEF separation was $\sim 2 \mathrm{~mm}$, comparable with that of ESTASI. As a result, it is possible to separately analyze samples fractionated into different bands by ESTASI-MS.

ESTASI-MS Detection of a Mixture of Peptides Separated by Gel IEF. To demonstrate the feasibility of using ESTASI as an interface of gel IEF and MS, a mixture of peptides was separated by gel IEF and then detected by ESTASI-MS. A bovine serum albumin (BSA) tryptic digest sample was loaded on an IPG strip and separated by IEF electrophoresis. After separation, ESTASI was performed on different regions of the gel to analyze the separated peptides. The identification results from four droplets added onto different regions of the gel are shown in Figure 4 and Supporting Information SI-4, including an area close to the anode $(\mathrm{pH}=4)$, an area with $\mathrm{pH}$ around 5.8, an area with $\mathrm{pH}$ around 6.2 and an area close to the cathode $(\mathrm{pH}=7)$. In total, $28,13,19$, and 13 peptides were identified from the four areas, respectively, with good $\mathrm{pI}$ matching. Combining the results obtained from these 4 spots, the identification sequence coverage of BSA digest was found to be $74 \%$ (Supporting Information Scheme SI-4). Indeed, several ESTASI-MS sprays were obtained from one droplet. Here, we show only one of several mass spectra obtained from the same droplet.

For comparison, two parallel control experiments were performed, including OFFGEL IEF-ESI-MS and gel based IEFMALDI-MS, which are standard methods used for peptide identification. In the case of OFFGEL IEF, samples were directly taken from the wells above the IPG strip. The ones close to the anode, above the areas with $\mathrm{pH}$ around 5.8 and 6.2, and close to the cathode were selected for ESI-MS identification (Thermo LTQ Velos). 12, 13, 10, and 5 peptides were identified from the four wells, respectively, and the identification sequence coverage summed from the four wells was found to be $48 \%$, Supporting Information SI-6. In the case of IEF-MALDI-MS, the IPG strip was cut into small pieces after IEF. The peptides were extracted from the gels, in the areas close to anode, with $\mathrm{pH}$ around 5.8 and 6.2, and close to cathode, for MALDI-MS analysis (Bruker MicroFlex LRF). In total, $12,9,8$, and 8 peptides were identified, respectively, and the identification sequence coverage summed from the four areas was found to be $47 \%$, Supporting Information SI-5. These

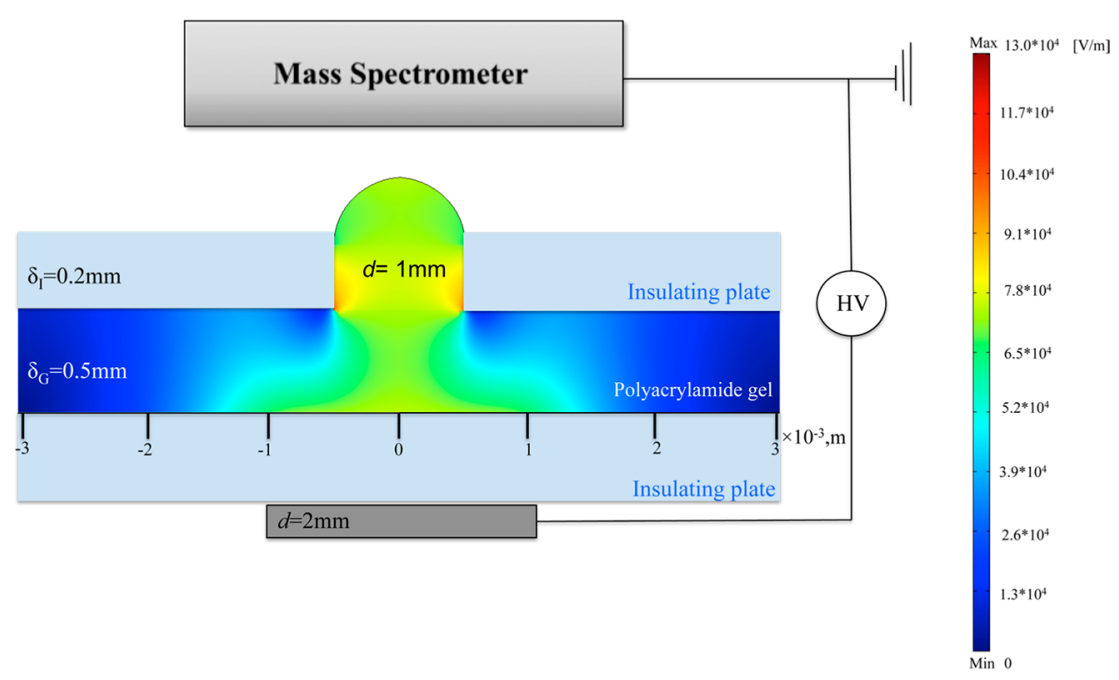

Figure 3. Finite element simulation of electric field in a polyacrylamide gel during sample extraction from the gel to the droplet. 
anode

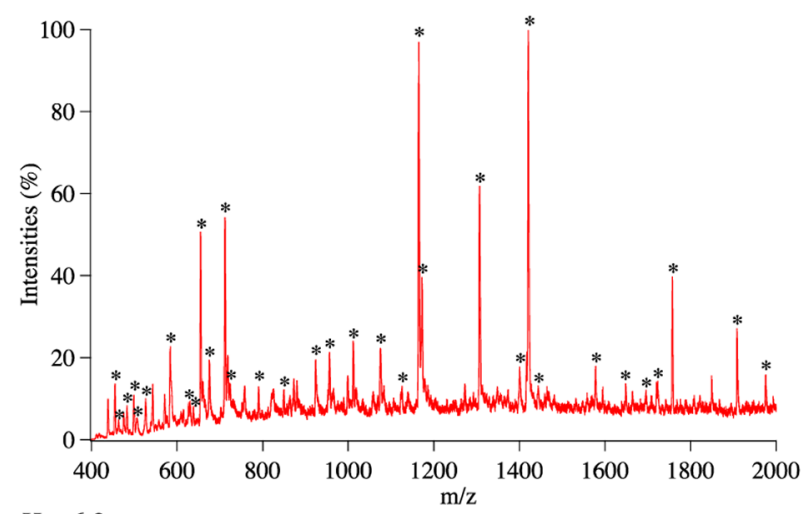

$\mathrm{pH}=6.2$

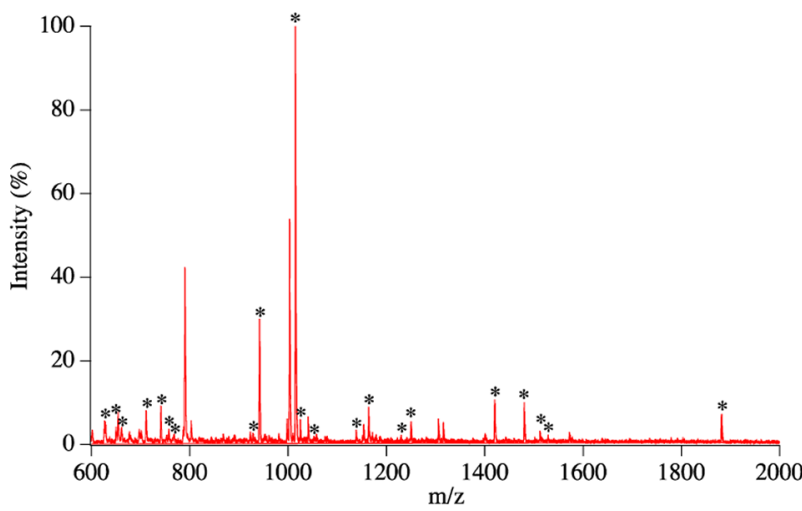

$\mathrm{pH}=5.8$

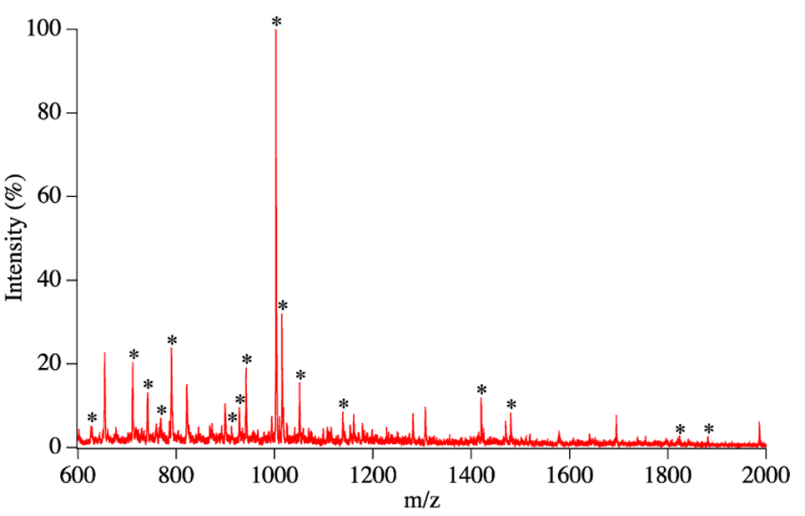

cathode

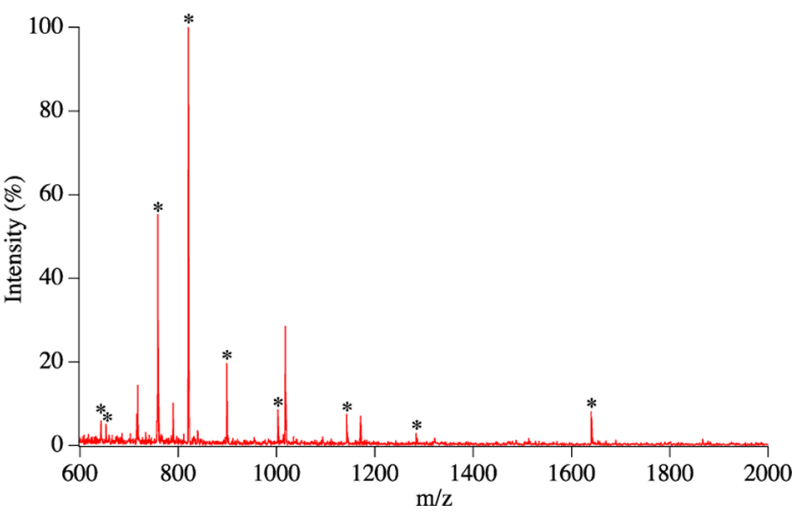

Figure 4. Mass spectra of BSA tryptic digest $(5 \mu \mathrm{L}, 56 \mu \mathrm{M})$ separated by IEF on an IPG strip under positive MS mode. The ions were generated by ESTASI from different areas of the gel. A pulsed positive high potential $(6.5 \mathrm{kV})$ was applied to the electrode. The peaks may correspond to singly, doubly or triply charged ions. The detailed information on the identified peaks is shown in Supporting Information SI-4.

results clearly show that ESTASI provides an efficient coupling strategy between polyacrylamide gel IEF separation and MS identification. Considering the high sequence coverage, this method can be applied for protein structure characterization in protein species proteomics. Besides, the combination of IEF with MS can provide information on peptide isoelectric point as well as peptide molecular weight, resulting in a highly confident identification even with low resolution mass spectrometer, such as ion trap, and without tandem MS. ${ }^{29}$

ESTASI-MS in the Analysis of Protein Mixtures Separated by Gel IEF. An important potential application of the IEF gel ESTASI-MS is direct analysis of proteins, which can be used in top-down proteomics in combination with other techniques, such as ultrahigh resolution mass spectrometer and gas phase fragmentation of intact proteins. In Figure 1, we have demonstrated that proteins can be directly ionised from a gel by ESTASI. However, with the current techniques available in our lab, it is hard to go further for the identification of unknown proteins, since only intact molecular weight of protein can be obtained yet not very accurate with the ion trap mass spectrometer.

To demonstrate the feasibility of ionizing proteins from a complex background, we have applied this strategy to an E. coli protein extract spiked with myoglobin and cytochrome c. Shown as Supporting Information SI-7, myoglobin and cytochrome $\mathrm{c}$ were identified from the complex protein mixture after IEF separation and ESTASI-MS. Mass spectra for E.coli extract were also obtained but the proteins identification could not be realized as mentioned before. Nevertheless, we have realized the in situ ionization of samples from the gel, which can be the beginning of an important development for direct coupling gel electrophoresis to MS, especially when combined with more advanced MS at the back end. In the current work, the gel ESTASI-MS is developed only based on polyacrylamide gel with constant $\mathrm{pH}$ or immobilized $\mathrm{pH}$ gradient. Since the ESTASI holds a similar mechanism as electrospray ionization, ${ }^{26}$ it is largely influenced by the presence of salts and SDS. Indeed, detection of sample by ESTASI-MS from SDS-PAGE is quite difficult. The usage of salts, SDS and surfactants should be avoided during ESTASI-MS detection.

\section{CONCLUSION}

In conclusion, we have developed a strategy to couple IEF gel electrophoresis with MS using electrostatic spray ionization. Proteins/peptides can be profiled after electrophoretic separation without extra processing steps. This direct coupling of ESTASI-MS with IEF gel separation improves the detection sensitivity compared with the classic Coomassie Brilliant Blue staining, with small amounts of target proteins or peptides as low as $20 \mathrm{ng}$ or $1 \mathrm{ng}$ in a band detectable, respectively. The strategy is also demonstrated as a more powerful method to couple gel IEF with MS than the developed standard methods. With these proof of concept results, we could expect the ESTASI-MS method to be applied in a variety of research fields, not only in the profiling of gels but also the imaging of chemicals on any surface. 


\section{ASSOCIATED CONTENT}

\section{S Supporting Information}

Electronic circuit and Labview program to synchronize two switches; ESTASI-MS detection of cytochrome $c$ in gel with the help of a plastic cover patterned with holes; Spatial resolution of gel ESTASI-MS with smaller electrode and patterned holes; Peptides identified from BSA digest by IEF-ESTASI-MS; Peptides identified from BSA digest by IEF-MALDI-MS; Peptides identified from BSA digest by OFFGEL IEF-ESIMS; IEF-ESTASI-MS analysis of Escherichia coli protein extract spiked with myoglobin and cytochrome c. This material is available free of charge via the Internet at http://pubs.acs.org.

\section{(w) Web-Enhanced Feature}

Video of electrostatic spray from a microdroplet on the surface of a piece of immobilized $\mathrm{pH}$ gradient gel.

\section{AUTHOR INFORMATION}

\section{Corresponding Author}

*Fax: +41 (0)21 69336 67. Tel: +41 (0)21 69331 51. E-mail: hubert.girault@epfl.ch.

\section{Author Contributions}

${ }^{\S}$ L. Qiao and E. Tobolkina contributed equally.

Notes

The authors declare no competing financial interest.

\section{ACKNOWLEDGMENTS}

Funding was provided by Swiss National Science Foundation "Analytical tools for proteome analysis and redoxomics (200020-127142)”. The authors acknowledge Dmitry Momotenko from Laboratoire d'Electrochimie Physique et Analytique, Ecole Polytechnique Fédérale de Lausanne for his help in numerical simulations.

\section{REFERENCES}

(1) Aebersold, R.; Mann, M. Nature 2003, 422, 198-207.

(2) Karas, M.; Hillenkamp, F. Anal. Chem. 1988, 60, 2299-2301.

(3) Tanaka, K.; Waki, H.; Ido, Y.; Akita, S.; Yoshida, Y.; Yoshida, T.; Matsuo, T. Rapid Commun. Mass Spectrom. 1988, 2, 151-153.

(4) Covey, T. R.; Bruins, A. P.; Henion, J. D. Org. Mass Spectrom. 1988, 23, 178-186.

(5) Fenn, J. B.; Mann, M.; Meng, C. K.; Wong, S. F.; Whitehouse, C. M. Science 1989, 246, 64-71.

(6) Wolters, D. A.; Washburn, M. P.; Yates, J. R. Anal. Chem. 2001, $73,5683-5690$

(7) Jungblut, P. R.; Holzhuetter, H. G.; Apweiler, R.; Schlueter, H. Chem. Cent. J. 2008, 2, 16.

(8) Jungblut, P.; Thiede, B.; ZimnyArndt, U.; Muller, E. C.; Scheler, C.; WittmannLiebold, B.; Otto, A. Electrophoresis 1996, 17, 839-847.

(9) Smith, L. M.; Kelleher, N. L. Nat. Methods 2013, 10, 186-187.

(10) Kelleher, N. L. Anal. Chem. 2004, 76, 196A-203A.

(11) Bogdanov, B.; Smith, R. D. Mass Spectrom. Rev. 2005, 24, 168200.

(12) Wu, S.; Lourette, N. M.; Tolic, N.; Zhao, R.; Robinson, E. W.; Tolmachev, A. V.; Smith, R. D.; Pasa-Tolic, L. J. Proteome Res. 2009, 8, 1347-1357.

(13) Tran, J. C.; Zamdborg, L.; Ahlf, D. R.; Lee, J. E.; Catherman, A. D.; Durbin, K. R.; Tipton, J. D.; Vellaichamy, A.; Kellie, J. F.; Li, M. X.; Wu, C.; Sweet, S. M. M.; Early, B. P.; Siuti, N.; LeDuc, R. D.; Compton, P. D.; Thomas, P. M.; Kelleher, N. L. Nature 2011, 480, 254-258.

(14) Gorg, A.; Weiss, W.; Dunn, M. J. Proteomics 2004, 4, 36653685.

(15) O'Farrell, P. H. J. Biol. Chem. 1975, 250, 4007-4021.

(16) Vesterberg, O. Biochim. Biophys. Acta 1972, 257, 11-19.
(17) Fawcett, J. S.; Dedman, M. L.; Morris, C. J. O. FEBS Lett. 1969, 3, 250-252.

(18) Righetti, P. G. Isoelectric focusing: theory, methodology and applications; Elsevier biomedical press: Amsterdam, 1983.

(19) Shimura, K. Electrophoresis 2009, 30, 11-28.

(20) Ros, A.; Faupel, M.; Mees, H.; van Oostrum, J.; Ferrigno, R.; Reymond, F.; Michel, P.; Rossier, J. S.; Girault, H. H. Proteomics 2002, 2, $151-156$

(21) Awdeh, Z. L.; Williams, A. R.; Askonas, B. A. Nature 1968, 219, 66-67.

(22) Canas, B.; Lopez-Ferrer, D.; Ramos-Fernandez, A.; Camafeita, E.; Calvo, E. Brief. Funct. Genomics Proteomics 2006, 4, 295-320.

(23) Inutan, E. D.; Trimpin, S. Mol. Cell. Proteomics 2013, 12, 792796.

(24) Trimpin, S.; Inutan, E. D. Anal. Chem. 2013, 85, 2005-2009.

(25) Takats, Z.; Wiseman, J. M.; Gologan, B.; Cooks, R. G. Science 2004, 306, 471-473.

(26) Qiao, L.; Sartor, R.; Gasilova, N.; Lu, Y.; Tobolkina, E.; Liu, B.; Girault, H. Anal. Chem. 2012, 84, 7422-7430.

(27) Zhang, L.; Su, X.; Liu, S.; Knapp, A. R.; Parthun, M. R.; Marcucci, G.; Freitas, M. A. J. Proteome Res. 2007, 6, 81-88.

(28) Girault, H. H. Analytical and Physical Electrochemistry (Fundamental Sciences), 1st ed.; EPFL Press: Lausanne, 2004.

(29) Cargile, B. J.; Stephenson, J. L. Anal. Chem. 2004, 76, 267-275. 